\title{
La memoria y sus desencuentros ${ }^{1}$
}

Francisco Delich

1. Cuánto importan las coincidencias en la historia, es materia opinable. «Dios no juega a los dados» dicen que dijo alguna vez Albert Einsten. Pero los hombres sí, agrego para mí, y tal vez -por qué noDios también. Entre la necesidad y el azar histórico existen las coyunturas, una reunión singular (y por eso mismo irrepetible) de circunstancias, actores, climas y humores sociales, que no reconoce un solo precedente causal sino varios, de distinta entidad y significación. La coyuntura parece una versión menor de la historia (y suele tratarse despectivamente) porque reconoce y revalúa lo efímero. Pero efímero no es sinónimo de insignificante en el sentido estricto del término; un gesto efímero transformó la historia de la humanidad en no pocas ocasiones.

Nada tan efímero ni bello como una mariposa. Sin embargo no podemos imaginar el verano sin las mariposas. No hay nada tan efímero como una protesta social; tampoco podemos imaginar una sociedad construyendo sin protestas su propia historia. Las mariposas son tan constitutivas del verano como la protesta de las sociedades. Significado ambiguo de lo efímero y de las coyunturas: como poetas menores, no tienen derecho al olimpo de la trascendencia. Pero de repente su memoria reaparece, como un relámpago (otro accidente, otro efímero) iluminando nuestro futuro.

La coyuntura, por definición, es irrepetible y la repetición de un fenómeno es condición necesaria para su legalidad. A su vez, la legalidad es condición esencial de la cientificidad. Así, entonces, por definición, no podemos pensar científicamente -ni aun con las prevenciones con las cuales el atributo ciencia debe ser utilizado en el espacio de las ciencias sociales- una coyuntura.

La coyuntura, en esta perspectiva, se acerca más a la historia que a la sociología. Es más apropiado y claro un análisis histórico que un

\footnotetext{
${ }^{1}$ Prólogo a la cuarta edición de DELICH, Francisco, (1994), Crisis y Protesta Social. Córdoba
} 1969. Buenos Aires: Fundación Universidad Córdoba. 
análisis sociológico. La sociología ingresa como condición, como cuadro, como contexto en el cual se presentan actores y conductas que terminan significando acontecimientos. Cuesta entonces situar el análisis coyuntural en parámetros estrictamente científicos y sociológicos; sin embargo, la riqueza de un análisis que reúna teoría con datos significativos, que piense la sociedad en movimiento, con una consciencia opaca y oscilante de la misma, es probablemente más rica que la mera relación de acontecimientos singulares, despojados de toda tentativa de explicación mayor. En cambio son definitivamente efímeras -olvidables- las lecturas coyunturales de la coyuntura, casi siempre conspirativas.

La protesta cordobesa que evocamos contó también con esta clase de lectores, según veremos. Aquella hipótesis no ha perdurado porque eran coincidencias fotográficas con las circunstancias; despojaban al azar de cualquier encanto, sometiendo la coyuntura a la grosería de la lectura lineal, codificada por agentes de inteligencia para ser decodificada por astutos e insatisfechos analistas.

La coyuntura -como ésta que se describe en el libro original- puede ser encapsulada en un momento de la historia porque constituye realmente un momento, un punto de inflexión, aunque también desborda la capsula que la contiene; la coyuntura tiene efecto sobre el mediano plazo, sobre la estructura y en consecuencia será leída retrospectivamente. Nada será igual en la historia argentina después de esa coyuntura. El poder encontró un límite para su acción; veinticinco años después, cuando una protesta algo violenta y circunstancial reclama la memoria del Cordobazo, la memoria registra el parecido pero rechaza la significación.

Ninguna protesta inmediatamente posterior fue lo mismo. Ni el llamado vivorazo ni las protestas de General Roca o Rosario son asimilables.

El Cordobazo se parece más en este sentido histórico a la Reforma Universitaria que a protestas aparentemente similares. Está lejos del mayo francés por contexto y por acción, o de las protestas en los campus californianos que se produjeron entonces.

Con ambas tiene en común el protagonismo estudiantil. Pero la construcción social del evento es radicalmente distinta por la distinta significación del movimiento estudiantil en sociedades industrializadas como Estados Unidos y Francia y sociedades pre-industrializadas como Argentina. Puede advertirse que escribo deliberadamente 
«industrializadas» y no modernizadas porque Argentina comparte con Estados Unidos y Francia la modernidad pero no comparte la industrialización.

2. El libro se escribió al calor de los acontecimientos, del propio movimiento social, cuando todavía no se pensaba en una teoría de los movimientos sociales, que aparecería algunos años después. Los primeros capítulos se escribieron y difundieron en la revista Jerónimo. El ensayo se completó en Tolouse durante el verano (nuestro) de 1970. Un amigo entrañable, Miguel Angel Piccato la dirigía. Exiliado en México después del ataque salvaje del lopezreguismo a La Voz del Interior, Piccato reeditó este libro, con el texto que aquí se entrega hacia 1978, cuando todos buscábamos con desesperación intelectual y política un camino claro en medio de la confusión, el desánimo, la violencia, el sectarismo, en fin, un camino sólido en un clima tenazmente opresivo. Para muchos de nosotros, 1978 fue el año de la inflexión. Fue entonces cuando se produjeron las rupturas definitivas y los encuentros también definitivos. La democracia política nos convocó para un proyecto de largo plazo que perdura todavía. En ese mismo año fundamos Crítica y Utopía.

Eran actos de esperanza y de coraje. Habíamos desafiado a la dictadura de Onganía con Jerónimo, habíamos contribuido a derrotarla. Habíamos reunido la razón y la acción. El futuro no se nos escaparía. ¿No se escaparía?

La segunda edición del libro había sido retirada de circulación, apenas aparecida, por la editorial Siglo XXI cuando cerraron su oficina en Buenos Aires. Conservo aún muchos ejemplares de esta segunda edición. Sin embargo prefiero la primera porque está centrada en el propio momento. Es la que utilizamos en la presente, sin modificaciones.

3. Aquellos eran tiempos de desprecio para el Estado. Desde dos vertientes.

Por una parte, la izquierda autoritaria había comenzado a descubrir -de la mano de Kruschev- los horrores del estalinismo. A fines de los cincuenta era claro para cualquiera que la dictadura del proletariado y la policía de Beria era parte del propio proceso leninista; no era posible separarlos en la práctica y en consecuencia ¿Cómo hacerlo en la teoría? Por otra parte, el romanticismo revolucionario encontró una reencarnación en Ernesto Guevara. El elitismo revolu- 
cionario, un cierto mesianismo y por supuesto una diferenciación del aparato soviético y de los partidos comunistas ortodoxos, ponían a sus seguidores en las antípodas del Estado. Y también los liberales. Faltaría mucho para que llegara la Sra. Thatcher al poder, nadie podía imaginar a Vargas Llosa en otro metier diferente a la literatura. La posguerra caliente ni la guerra fría eran contextos apropiados para satanizar al Estado en ninguna parte.

El singular encuentro entre románticos revolucionarios (más cerca de ácratas irredentos) y liberales ortodoxos se producía en el común rechazo al poder estatal. Para los primeros no era sino enajenación, opresión, burocracia inútil. Para los segundos, también un despilfarrador de recursos sociales, agente de odiosas interferencias al mercado.

El Estado de derecho o el Estado autoritario, ambos eran considerados igualmente perniciosos aunque podían optar finalmente por el Estado de Derecho, solamente como un mal menor.

El concepto (y el uso) de la sociedad civil emergía intensamente. Más intensamente cuanto menos democrático el contexto político; disueltos los partidos políticos, clausurados sus locales, la dictadura personal de Onganía se veía a sí misma como un fenómeno de larga duración; primero la economía, después la sociedad y finalmente la política. Esos eran los tiempos previstos explícitamente en un discurso que postulaba a Onganía como el Bismarck argentino, listo para construir en veinte años de dictadura la grandeza nacional.

En ese contexto de 1966/1969 es obvio que la sociedad civil, carente de articulación con el Estado, sólo podría recostarse en ella misma, separarse del Estado primero, desconocerlo enseguida y desafiarlo finalmente.

El rechazo profundo del Estado realmente existente (estalinista en la Unión Soviética, autoritario en América Latina), incluía un rechazo a las formas políticas tradicionales y de los partidos políticos en primerísimo lugar. Pero entonces ¿Quién defendía al Estado si revolucionarios y burgueses aspiraban a suprimirlo? Las corporaciones realmente existentes: la corporación sindical, la corporación universitaria, la corporación empresarial, la corporación rural, etcétera.

El modelo de desarrollo prevaleciente -industrialización por sustitución de importaciones, predominio agro-exportador, economía cerrada, subsidios regionales, bajos impuestos, expansión del empleo público, sistemas de precios monopólicos u oligopólicos- tenía 
en el Estado una herramienta imprescindible y en las corporaciones el único puente sólido de encuadramiento de la sociedad civil.

4. Germani había dejado la Argentina en 1966, contratado como profesor en Harvard. Estaba harto de la ortodoxia autoritaria que lo tenía como objeto predilecto de ataques intelectuales. El golpe de junio no hizo más que apresurar su decisión. Se fue Germani para no regresar jamás, salvo casualmente como un visitante ilustre. Cuando se jubiló en Harvard hacia 1976, volvió a Roma. Allí murió en 1979. A mediados de 1970 estaba de paso en Buenos Aires. Un amigo, Panxo Marsal, me llamó a Córdoba. Me dijo que Germani había leído el libro y que le gustaría discutirlo conmigo.

Nos encontramos en un hotel de la calle Cerrito cerca de la medianoche. Yo había leído bien (sin contemplaciones) a Germani, le tenía, como todos, un inmenso respeto intelectual y personal pero no era por entonces ni su alumno ni su amigo. Le había conocido personalmente a fines de los cincuenta y lo había reencontrado en París donde participé en un seminario en 1963.

Estaba Germani con Panxo y otras personas que no conocía, me agregué a aquella mesa de conversaciones cruzadas hsta que terminados los saludos, y también las pequeñas nostalgias, me dijo con simplicidad: «Su libro me gustó. Ahora dígame, ¿Cuál es la diferencia entre la anomía y la crisis orgánica?». La madrugada se convertía en mañana, y seguíamos, café tras café, cigarrillo tras cigarrillo; un interminable y apasionante intercambio de ideas y emociones. Aquella noche nos hicimos amigos para siempre.

Así nomás. Anomía y crisis orgánica, Durkeim y Gramsci evocados en relación a un pequeño ensayo semiperiodístico.

Conocía razonablemente a Durkheim porque unos años antes, en 1962/1963, había seguido un curso de Raymond Aron dedicado a Durkeim y Weber. De Gramsci había leído desordenada y parcialmente sólo algunos textos; pero tenía -si necesario- el incomparable apoyo logístico intelectual de Aricó, lejos, el mejor conocedor de Gramsci en estas latitudes. Para los jóvenes comunistas como Aricó, Gramsci era el puente que les permitía transitar del autoritarismo leninista hacia formas de socialdemocracia, de una visión esquematizada de las clases sociales a una perspectiva capaz de incorporar fenómenos sociales latinoamericanos, apartarse de concepciones verticales como el centralismo democrático en las organizacio- 
nes políticas y aproximarse a nociones horizontales y participativas. Para quienes debutaban políticamente en el marco de partidos populares como el radicalismo y el peronismo, Gramsci era un puente al socialismo capaz de reconocer identidades y movimientos populares. Me sentía entonces más cerca de Durkheim que de Gramsci, sin embargo no encontré la respuesta adecuada.

Ahora lo diría con solvencia y seguridad, no tanto por evolución intelectual sino por estos veinticinco años transcurridos. No hubo diría- ni anomia ni crisis orgánica, porque son categorías que no sirven para el análisis coyuntural. Sólo son aplicables en análisis de mediano y largo plazo.

Pero esto es una respuesta teórica y metodológica. Habría agregado que la colonización social del Estado estaba mostrando sus primeros síntomas. Probablemente habría señalado la debilidad del Estado autoritario, su vulnerabilidad a las corporaciones, la consistencia creciente de la sociedad civil, la notoria inmadurez de las clases o élites dirigentes.

Pero el argumento más sólido estaría, seguramente, ligado a un replanteo de la teoría del Estado en relación a una Teoría de la Sociedad. Cuando el Estado exuda autoritarismo, ha perdido su razón de ser, la salvaguarda de la libertad. El Estado no se inventó para oprimir sino para evitar-casualmente- las opresiones, comenzando por acotar la peor de todas, la propia opresión social.

Pero este tema merece más que una referencia incidental. Si recupero aquella anécdota es porque el encuadre teórico es parte de la memoria histórica, contribuye a esclarecer el discurso pasado y el discurso presente.

Si la más decisiva irrupción de la modernidad en Occidente la constituye la Revolución Francesa, dos siglos después se ha convertido en el sustento mayor de la democracia contemporánea. Setenta y dos años después de la Reforma Universitaria como episodio, es ahora conciencia pública el valor de la democracia universitaria. Veinticinco años después del Cordobazo, su herencia mayor es la democracia en el país. La construcción de la democracia sólida y perdurable no se nutre solo de afirmaciones, sino también de negaciones.

5. El cordobazo como episodio, como coyuntura, tiene como se está viendo su propia significación. Pero también se inscribe en historias parciales, en la historia de la clase obrera, en la historia del movi- 
miento estudiantil, en la historia global de la cultura política urbana de Córdoba.

Por aquellos años se discutía acerca del rol de la clase obrera y de los sindicatos en los términos habituales de entonces, de los sesenta. La opción política de los sindicatos estaba condicionada por su propia condición y su relación con el Estado y por los marcos simbólicos de referencia, probablemente en ese orden.

La clase obrera cordobesa, después de la radicación de grandes plantas industriales, había mudado piel. La Fábrica Militar de Aviones quedaba como un antecedente. Hasta allí era el mayor complejo industrial de la provincia; pero de capital estatal, más tarde o más temprano, el carácter del capital marca las conductas: los obreros se parecen más a empleados públicos que propiamente a obreros industriales.

La radicación de IKA (luego Renault, CIADEA) implicó una concentración obrera significativa para la ciudad tanto en términos económicos como sociales. Aportó culturas propiamente fabriles (en el peor y en el mejor sentido) y generó cambios en la relación de fuerzas internas del conjunto gremial organizado.

El trabajo era duro (en algunos casos dramático, como los hornos de Forja que estudiamos entonces y cuyos resultados publicamos no sin alarma), insalubre (como la sección pinturas, robotizada ahora), o simplemente rutinario, como en cualquier cadena de montaje. Pero las fábricas pagaban muy bien, puntualmente, y el sindicato ofrecía beneficios adicionales a través de la obra social.

De modo que a fines de los sesenta, los obreros de IKA Renault podían quejarse de su trabajo pero no de sus sueldos. Eran los obreros mejor pagados del país. ¿Por qué su participación tan decisiva en el cordobazo? Por eso justamente, como lo sostuve en el libro. Los hambrientos sólo querrían y -tal vez- se conformarían con la comida. Pero los que comen y producen pueden reivindicar no solamente la comida sino también la ciudadanía. Eso hizo la clase obrera de Córdoba en 1969.

Otros sectores obreros, más pequeños numéricamente pero bien organizados como LUZ Y FUERZA, o estratégicos como UTA, contribuyeron sin duda, pero ninguno sin embargo marcó tanto el episodio como la marcha de SMATA desde Santa Isabel hasta la vieja plaza Vélez Sarsfield. En cualquier caso estos tres gremios, cuyas conducciones lideraron la protesta, tenían un común denominador: estaban entre los mejores pagados del país. 
Ciertamente los gremios tenían razones específicas para las protestas porque la supresión del llamado sábado inglés los perjudicaría. Tenían también reivindicaciones particulares referidas a las condiciones de trabajo. Pero ninguno era tan fuerte como para desencadenar una protesta de esa magnitud. Sólo la conciencia de un rechazo profundo de estilos y de contenidos del Programa y Proyecto Onganía, del gobierno local sustentado en restos oligárquicos, un rechazo al clima opresivo instalado entre jóvenes y adolescentes. En fin, la protesta crece y se desarrolla cuando desaparecen hasta los últimos canales de comunicación entre gobierno y sociedad. Los canales informales se habían roto, por los menos un año antes de estos episodios. El gobierno nacional giraba en torno al vacío político desde mediados de 1967 y en el vacío social desde comienzos de 1968. La crónica de aquellos años puede ilustrar razonablemente esta hipótesis. El propio Ejército había hecho crisis con el relevo de su comandante en jefe. El general Alsogaray fue reemplazado por el general Lanusse. La intranquilidad en el ejército se agudizó a la hora de reprimir el alzamiento cordobés. Como es sabido, muchos atribuyeron al general Lanusse cierta complicidad en la protesta, por no haber ordenado la movilización de sus tropas rápidamente. Los primeros incidentes importantes, los primeros muertos y heridos se produjeron hacia las diez de la mañana del 29 y el ejército intervino hacia las cinco de la tarde. El general Lanusse lo desmintió siempre.

6. El peor recuerdo de aquel 1966 lo mantiene la universidad. Recuperada su autonomía a partir de 1956, estaba viviendo un período de florecimiento de las ciencias y las artes. Aunque con exageraciones variadas, la creación de un aparato científico tecnológico por parte de B. Houssay, el pluralismo ideológico, la actualización en las ciencias sociales que había producido José Luis Romero y Gino Germani entre otros, la proliferación de revistas y actividades académicas, hacían de la universidad un espacio social e intelectualmente atractivo.

La intervención a las universidades, triste noche de los bastones largos en la UBA, el éxodo de profesores e investigadores altamente calificados, troncharon una evolución optimista para el país.

El golpe de junio interrumpió un desenvolvimiento institucional con defectos obvios pero corregibles y sobre todo interrumpió la consolidación de una estructura científico/tecnológica moderna. 
Los estudiantes fueron doblemente afectados. Por una parte descendió inmediatamente el nivel académico. Por otra se instaló entre 1966 y 1969 un clima opresivo dentro de la Universidad. La reunión de autoritarismo y mediocridad suele ser letal para las universidades. La mediocridad no es poca cosa. El autoritarismo es peor. Pero la reunión de ambos insoportable.

La protesta era previsible y no se hizo esperar. Curiosamente la protesta más radical no partía de la Universidad Nacional sino de la reciente Universidad Católica. Cuando el cordobazo se produjo, la Universidad se estremeció. Y en su interior, ya nada fue igual. La respuesta se concretó un par de años después, cuando el general Lanusse, ya presidente de la transición a la democracia, comenzó a reincorporar docentes excluidos y creó, de una sola vez, una docena de universidades. Como Haussmann en el siglo pasado, abriendo avenidas en París para evitar las excesivas concentraciones sociales en espacios reducidos, el gobierno creó universidades en todas partes para evitar el potencial contestatario de estudiantes mal atendidos.

Por supuesto, se trata de situaciones objetivas. Había también subjetividades en construcción. Pocos sectores sociales son tan sensibles al orden simbólico como los estudiantes. La activa participación en el cordobazo lo demostró una vez más.

7. A veinticinco años de distancia, sigo teniendo como válida mi primera hipótesis intuitiva. El gran protagonista fue aquella incipiente sociedad urbana cordobesa. Reconocer la importancia de las organizaciones gremiales y políticas no mengua el carácter decisivo del acompañamiento social al paro activo. Como es obvio, la significación social sólo puede construirse desde la propia sociedad y esto es lo que ocurrió con el cordobazo entonces y ahora.

Aquella sublevación popular impelía hacia la superficie las ambigüedades y contradicciones de una aldea en crecimiento, devenida ciudad casi sin conciencia, pero siguiendo los rigores de la mutación; las pequeñas élites provincianas, estaban cediendo su lugar a futuros capitanes de industrias; la clase media se expandía a la nueva clase obrera industrial, los estudiantes dejaron de ser una minoría ilustrada para conformar un grupo social cualitativamente significativo. La sociedad mutaba arriba y abajo, y esta conmoción en cierto modo la unificaba en el estilo de la revuelta. 
¿Ha cambiado el autor? Con toda seguridad, pero no tanto como para no reconocer sus propias huellas. Ha cambiado la mirada pero no el horizonte. Pero este es un detalle que sólo importa a algunos pocos. El texto, ajeno a toda tutela debe hablar por sí mismo.

Córdoba, mayo de 1994 